\title{
Multifunctional Mitochondrial AAA Proteases
}

\author{
Steven E. Glynn * \\ Department of Biochemistry and Cell Biology, Stony Brook University, Stony Brook, NY, United States
}

OPEN ACCESS

Edited by:

Walid A. Houry,

University of Toronto, Canada

Reviewed by:

Eyal Gur,

Ben-Gurion University of the Negev

Nico P. Dantuma

Karolinska Institutet, Sweden

Johannes Herrmann,

Kaiserslautern University of

Technology, Germany

*Correspondence:

Steven E. Glynn

steven.glynn@stonybrook.edu

Specialty section:

This article was submitted to Protein Folding, Misfolding and

Degradation,

a section of the journal

Frontiers in Molecular Biosciences

Received: 30 March 2017

Accepted: 08 May 2017

Published: 22 May 2017

Citation:

Glynn SE (2017) Multifunctional Mitochondrial AAA Proteases.

Front. Mol. Biosci. 4:34.

doi: 10.3389/fmolb.2017.00034
Mitochondria perform numerous functions necessary for the survival of eukaryotic cells. These activities are coordinated by a diverse complement of proteins encoded in both the nuclear and mitochondrial genomes that must be properly organized and maintained. Misregulation of mitochondrial proteostasis impairs organellar function and can result in the development of severe human diseases. ATP-driven AAA+ proteins play crucial roles in preserving mitochondrial activity by removing and remodeling protein molecules in accordance with the needs of the cell. Two mitochondrial AAA proteases, i-AAA and $m-A A A$, are anchored to either face of the mitochondrial inner membrane, where they engage and process an array of substrates to impact protein biogenesis, quality control, and the regulation of key metabolic pathways. The functionality of these proteases is extended through multiple substrate-dependent modes of action, including complete degradation, partial processing, or dislocation from the membrane without proteolysis. This review discusses recent advances made toward elucidating the mechanisms of substrate recognition, handling, and degradation that allow these versatile proteases to control diverse activities in this multifunctional organelle.

Keywords: mitochondria, proteolysis, i-AAA, m-AAA, AAA+

\section{INTRODUCTION}

Mitochondria provide eukaryotic cells with a stage for performing essential activities, including mass ATP production, calcium ion storage, and fatty acid oxidation (Chan, 2006; McBride et al., 2006). These activities are coordinated by a diverse composite proteome encoded by genomes in both the nucleus and mitochondrial matrix (Anderson et al., 1981; Sickmann et al., 2003; Rhee et al., 2013; Calvo et al., 2016). Proteins synthesized in the cytosol must be imported into the organelle via a complex network of translocases, chaperones, and processing peptidases (Neupert and Herrmann, 2007). Once inside, mitochondrial proteins are exposed to damaging reactive oxygen species (ROS), by-products of oxidative phosphorylation (Beckman and Ames, 1998; Ugarte et al., 2010). Preserving mitochondrial function thus requires precise systems of proteostasis to balance the entry and exit of proteins into the organelle, remove damaged components to maintain uninterrupted activity, and respond to the changing energetic needs of the cell (Diaz and Moraes, 2008; Ugarte et al., 2010). One route for the removal of mitochondrial proteins is degradation by a network of proteolytic enzymes (Koppen and Langer, 2007). Together, these proteases select and destroy proteins to achieve a constant recycling of the mitochondrial proteome (Augustin et al., 2005). Absence of proper mitochondrial proteostasis is linked to the development of severe human diseases, including cancer and a host of neurodegenerative disorders (Bulteau and Bayot, 2011; Rugarli and Langer, 2012; Konig et al., 2016; Levytskyy et al., 2016). A recent report has suggested that the proteolytic capacity of mitochondria is used to clear cytosolic protein aggregates that are associated with aging (Ruan et al., 2017). 
Mitochondria are enveloped by outer (MOM) and inner membranes (MIM), which enclose the aqueous intermembrane space (IMS) and matrix, respectively. Consequently, both energydependent and independent proteases are located across the organelle operating in both polar and non-polar environments (Koppen and Langer, 2007). Two AAA+ family members, collectively named the mitochondrial AAA proteases, are anchored to the MIM and engage substrates on either side of the membrane (Leonhard et al., 1996). A number of recent studies have provided insight into the diverse roles played by the mitochondrial AAA proteases in maintaining function of the organelle. This review will focus on our current understanding of the structural and mechanistic principles that allow these enzymes to recognize, engage, and process protein substrates.

\section{AAA+ Proteins in Mitochondria}

Mitochondria contain a number of AAA+ ATPases that can be traced to ancestral bacterial enzymes present during symbiogenesis (for review see Truscott et al., 2010). These proteins contain the family-specific sequence motifs responsible for ATP binding and hydrolysis, and presumably assemble into canonical ring-shaped oligomers (Hanson and Whiteheart, 2005). A feature of the AAA+ family is the coupling of the energy of ATP hydrolysis to power highly diverse functions. In mitochondria, these activities include nonproteolytic chaperones, such as Hsp78, a functional homolog of Hsp104/ClpB that promotes disaggregation of matrix proteins (Leonhardt et al., 1993). Mitochondria also contain a number of $\mathrm{AAA}+$ proteases, including homologs of the well-studied soluble proteases, Lon (Pim1) and ClpXP, which remove oxidatively damaged proteins from the matrix (Wang et al., 1993; Suzuki et al., 1994; van Dyck et al., 1994; Corydon et al., 2000). Interestingly, yeast do not contain the ClpP proteolytic subunit and instead, the ClpX ATPase (Mcxlp) performs important nonproteolytic functions (van Dyck et al., 1998; Kardon et al., 2015). In bacteria, FtsH is a AAA+ zinc-metalloprotease that degrades substrates at the face of the plasma membrane. Two ATPdependent proteases, which are evolutionarily related to bacterial $\mathrm{FtsH}$, are found anchored to the mitochondrial MIM (Leonhard et al., 1996). Named i-AAA and m-AAA, these mitochondrial AAA proteases are positioned to interact with substrates in the IMS, matrix, or MIM (Leonhard et al., 1996, 2000; Koppen and Langer, 2007; Tatsuta and Langer, 2009; Gerdes et al., 2012; Figure 1).

\section{ORGANIZATION OF THE MITOCHONDRIAL AAA PROTEASES}

Both $\mathrm{i}$-AAA and m-AAA proteases encode multiple domains on a single polypeptide: small distal domains located across the MIM from the main body of the protease; an insoluble transmembrane (TM) domain; and a catalytic core comprising a AAA+ ATPase domain and a zinc metalloproteinase domain(Leonhard et al., 1996). The major architectural difference between them lies in the organization of the TM domains. The i-AAA contains a single transmembrane helix that, when inserted into the MIM, projects the ATPase and protease domains into the IMS. In contrast, the m-AAA protease contains two transmembrane spans that project the catalytic domains into the matrix. These opposing orientations allow both faces of the MIM and both aqueous compartments of the mitochondrion to be scrutinized for the appearance of substrates (Leonhard et al., 2000). In all eukaryotes, six identical i-AAA subunits assemble into an active proteolytic complex (YME1L in mammals; Yme1 in yeast). In contrast, multiple isoforms of m-AAA exist with distinct subunit compositions. In yeast, $\mathrm{m}-\mathrm{AAA}$ is an obligate heterohexamer of alternating Yta10 and Yta12 subunits (Yta10/12; Arlt et al., 1996). In mammals, the protease can either form AFG3L2 homohexamers or heterohexamers of alternating AFG3L2 and Paraplegin subunits. The distribution of these two isoforms is tissue specific, with a greater proportion of heterohexamers present in mitochondria of neuronal cells (Koppen et al., 2007).

The broad structural resemblance to the ancestral FtsHlike protease was confirmed by a moderate resolution cryoEM structure of Yta10/12 revealing an arrangement of stacked hexameric AAA+ and protease rings surrounding an axial pore (Suno et al., 2006; Bieniossek et al., 2009; Cha et al., 2010; Lee et al., 2011; Su et al., 2016; Figure 2A). As with other family members, the six ATP binding sites are predominately formed within individual $\mathrm{AAA}+$ domains with important additional interactions provided by neighboring subunits (Hanson and Whiteheart, 2005; Karlberg et al., 2009). The interfaces between $\mathrm{AAA}+$ domains provide a surface for communication and coordination between protomers. An elegant in vivo study using S. cerevisiae Yta10/12 demonstrated that ATP binding to Yta12 inhibits nucleotide hydrolysis in the neighboring Yta10 subunit (Augustin et al., 2009). Suppressor mutations and homology modeling revealed that the presence of a nucleotide $\gamma$-phosphate bound to Yta12 is sensed by a patch of conserved inter-subunit signaling residues on Yta10 and transmitted via the pore-2 loop to the Walker-B motif of Yta10. This allosteric coordination is proposed to create an alternating power stroke that maximizes the unfolding force while maintaining grip of the translocating substrate. The observation of similar coordination in Yta12 variants capable of forming homooligomers suggested that this phenomena could exist in related homohexameric proteases.

The lower ring sequesters the proteolytic active sites inside a compartment that can be accessed upon translocation through the axial pore. The active sites are formed by a canonical HEXXH motif that coordinates the water-activating zinc ion (Rawlings and Barrett, 1995; Leonhard et al., 1996). While peptide cleavage by many proteases is strongly influenced by the pattern of residues surrounding the scissile peptide bond, it remains to be seen if such cleavage site preferences exist for the mitochondrial AAA proteases. The protease domain of human AFG3L2 has been identified as a hotspot for mutations linked to the development of the human neurodegenerative diseases (Cagnoli et al., 2010; Di Bella et al., 2010; Pierson et al., 2011). For example, at least 17 single amino acid substitutions in AFG3L2 have been linked to the development of spinocerebellar ataxia type 28 (SCA28), a disorder characterized by imbalance, slurred speech and lack of limb coordination (Mariotti et al., 2008; Di Bella et al., 2010; Lobbe et al., 2014; Qu et al., 2015; Zuhlke et al., 


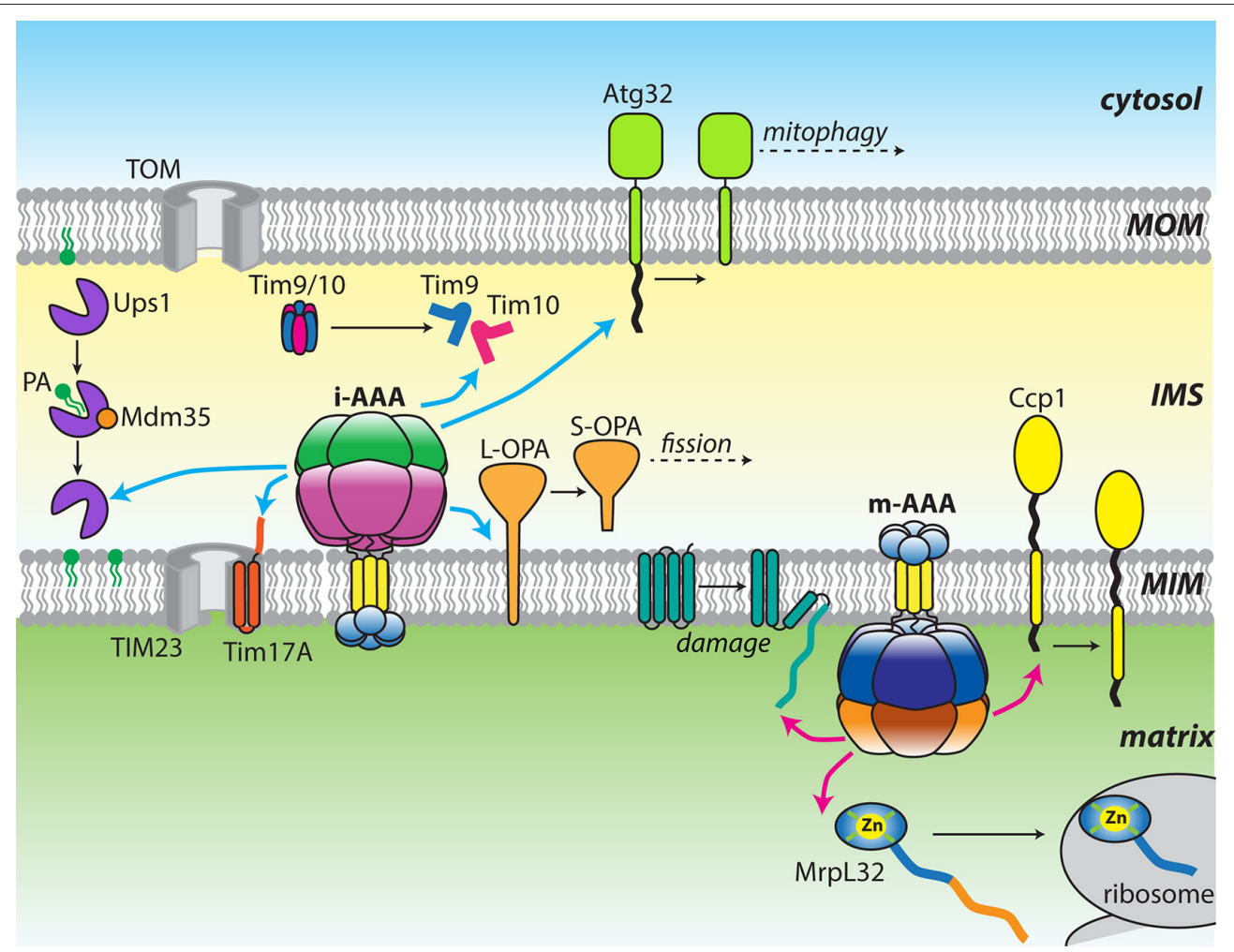

FIGURE 1 | Diverse functions of the mitochondrial AAA proteases. Cartoon showing a diverse array of substrates targeted by either yeast or mammalian i-AAA (cyan arrows) and m-AAA (pink arrows) proteases. Changes in substrate structure or arrangement are shown as black arrows.

2015; Svenstrup et al., 2017). Homology modeling using crystal structures of FtsH reveals these mutations largely cluster to positions surrounding the metalloprotease active site and subunit interfaces (Figure 2B) and thus are likely to cause defects in polypeptide cleavage and hexamer assembly rather than substrate binding or ATP hydrolysis.

Assembly of many AAA + oligomers is driven by interactions between ATPase domains. However, truncations of both human and yeast i-AAA lacking the TM and N-terminal domain (ND) fail to form active hexamers, highlighting the importance of interactions within these domains to oligomerization (Leonhard et al., 1999; Shi et al., 2016). Furthermore, replacement of these domains with a synthetic hexamerization sequence was sufficient to drive assembly of active i-AAA proteases in vitro (Shi et al., 2016; Rampello and Glynn, 2017). FtsH also requires the TM domain to promote oligomerization (Akiyama and Ito, 2000). In contrast, assembly of m-AAA hexamers appears to involve additional interactions in the metalloprotease domain (Lee et al., 2011). Truncations of Yta10/12 lacking the distal IMS domain (IMSD) and TM could complement respiratory defects in $\Delta y t a 10 / \Delta y t a 12$ cells but displayed impaired degradation of integral membrane substrates, indicating the presence of unanchored but assembled hexamers in the matrix (Korbel et al., 2004). The interactions that specify the formation of defined heterooligomeric arrangements of different m-AAA proteases also appear to be located in the metalloprotease domain as substitution of only two residues was sufficient to drive assembly of homo-oligomeric Yta12 proteases (Lee et al., 2011).

The distal domains of both proteases contain $\sim 70-80$ folded residues but are positioned differently in their respective primary structures. The i-AAA ND immediately follows the mitochondrial targeting sequence and arranges in the matrix, whereas the m-AAA protease IMSD is encoded between the two transmembrane spans. Despite low sequence homology, a solution structure of the human AFG3L2 IMSD displays a strikingly similar $\alpha+\beta$ fold to the periplasmic domain (PD) of FtsH (Ramelot et al., 2013; Figure 2A). Highly conserved residues between these regions map to the interfaces of the FtsH PDs, implying the AFG3L2 IMSDs form a similar hexameric structure in the assembled protease (Scharfenberg et al., 2015). However, in detergent-solubilized full-length Yta10/12, the IMSDs do not interact directly but instead fan out from the TM domain (Lee et al., 2011; Figure 2A). NDs of i-AAA display no homology with domains of other metalloproteases and cluster into two distinct and evolutionarily unrelated families (Frickey and Lupas, 2004; Scharfenberg et al., 2015). Plant and fungal NDs belong to the tetratricopeptide repeat (TPR) fold, whereas NDs from animal sources have no known homologs and no structures have been determined (D'Andrea and Regan, 2003; Scharfenberg et al., 2015; Figure 2A).

In both cases, the functions of these distal domains remain unclear. The apparent diversity in the sequence and structure 


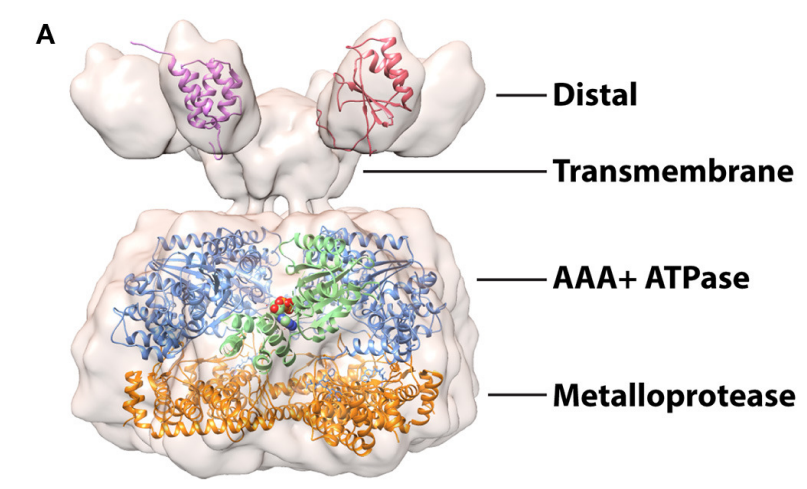

B

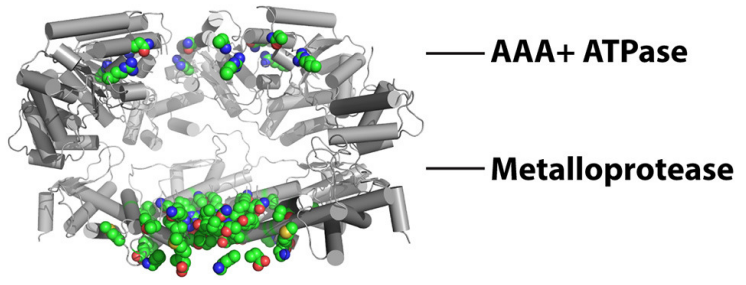

FIGURE 2 | Structures studies of mitochondrial AAA proteases (A) Combined structural information on the mitochondrial AAA proteases. A $12 \AA$ resolution cryoEM envelope is shown from full-length $S$. cerevisiae Yta10/12 (EMD-1712; Lee et al., 2011). Crystal structure of the AAA+ domain of human paraplegin bound to ADP at $2.2 \AA$ (green) (2QZ4; Karlberg et al., 2009). Crystal structure of the truncated FtsH from T. maritima at 2.6 $\AA$ (AAA+ domains, blue; protease domains, orange) (3KDS; Bieniossek et al., 2009). Solution structures of IMSD from human AFG3L2 at (red) (2LNA; Ramelot et al., 2013) and ND from S.cerevisiae Yme1 (pink) (2MV3; Scharfenberg et al., 2015). The figure was produced using UCSF Chimera (Pettersen et al., 2004). (B) Structure of T. maritime FtsH (3KDS) (Bieniossek et al., 2009) showing the positions of 17 mutations identified in SCA28 (green spheres).

of these domains may imply they simply act as anchors to stabilize the protease in the membrane during substrate extraction. Indeed, active reconstituted $\mathrm{i}$-AAA proteases lacking the ND and TM domain demonstrated that these domains are dispensable for ATP-dependent proteolysis (Shi et al., 2016). One possible function for these domains is the recognition of substrates on the opposite face of the membrane. Substrates presenting domains on both sides of the MIM appear to be fully degraded, implying translocation of polypeptides across the membrane leaflet but not necessarily transmembrane substrate recognition (Leonhard et al., 2000). The distal domains may also act as interaction surfaces for large protein assemblies that modulate protease function. The analogous FtsH PDs interact with the HflKC complex to promote degradation of uncomplexed subunits of the SecY protein translocase (Kihara et al., 1996, 1997; Akiyama et al., 1998). In all eukaryotes, two related prohibitin subunits, PHB1 and PHB2, form MIM-anchored heterodimeric ring structures with diameters of 20-25 nm (Tatsuta et al., 2005; Merkwirth and Langer, 2009). Both prohibitin subunits bear large C-terminal domains that project into the IMS where they are capable of interacting with the m-AAA IMSDs. Although, the precise interactions between the prohibitin ring and the protease are unclear, deletion of either subunit in yeast accelerates the degradation of non-assembled Cox3 by Yta10/12 (Steglich et al., 1999). In mammals, deletion of PHB2 increases the proteolytic processing of the mitochondrial fission regulator, OPA1 (Merkwirth et al., 2008). Thus, in both cases, the prohibitin ring appears to restrict the activity of the m-AAA protease. A recent study identified a multi-subunit proteolytic hub formed between mammalian YME1L and the MIM rhomboid protease PARL, mediated by the membrane scaffold protein SLP2 (Wai et al., 2016). Presence of this supramolecular SPY complex increased cleavage of the PINK1 kinase by PARL and processing of OPA1 by the nearby OMA1 protease. The location of SLP2 in the matrix invites suggestions of an analogous arrangement to the prohibitin ring, positioned on the opposite face of the MIM and interacting with the NDs of YME1L.

\section{MODES OF SUBSTRATE PROCESSING}

A commonly highlighted feature of the mitochondrial AAA proteases is the contrasting fates of different substrates. Proteins may be completely degraded to small peptide fragments, undergo partial processing to a fixed point in the structure, or be dislocated from the membrane without proteolysis. These outcomes are dependent on the identity of the substrate and allow just two proteases to control a wide variety of mitochondrial operations.

\section{Complete Substrate Degradation}

It has long been established that both mitochondrial AAA proteases can provide house-keeping functions by fully degrading damaged, misassembled, or unnecessary proteins in their respective compartments. Most of these substrates undergo processive proteolysis to generate small peptides that can be exported from the organelle or further processed by oligopeptidases (Alikhani et al., 2011; Quiros et al., 2015). This class of substrates includes misassembled components of the respiratory chain and $\mathrm{F}_{1}-\mathrm{F}_{0}$ ATP synthase complexes that must be precisely balanced to coordinate expression of both mitochondrial and nuclear encoded subunits (Nakai et al., 1995; Weber et al., 1995; Arlt et al., 1996; Kaser et al., 2003). Rapid turnover of these proteins is essential to prevent the buildup of potential aggregating proteins within the organelle. Accordingly, genetic loss of either protease results in severe phenotypes, including respiratory defects, loss of mitochondrial structure, and increased sensitivity to oxidative stress (Campbell et al., 1994; Tzagoloff et al., 1994; Stiburek et al., 2012). Recently, several more examples of this activity have been identified in a human embryonic cell line, including Ndufb6, ND1, and Cox4, important components of the oxidative phosphorylation machinery (Stiburek et al., 2012).

An increasingly clear role for these proteases is in the protection against mitochondrial stress arising from the accumulation of misfolded proteins (Rainbolt et al., 2014; Bohovych et al., 2015). Both i-AAA and m-AAA in mammals, and i-AAA from Arabidopsis are reported to degrade carbonylated proteins resulting from damage by ROS (Maltecca et al., 2009; Kicia et al., 2010; Stiburek et al., 2012; Smakowska 
et al., 2014). Additionally, stress-sensitive degradation of YME1L is used to reorganize the proteolytic capacity of the IMS (Rainbolt et al., 2015, 2016). Mitochondrial stress has significant consequences for the import of nuclear-encoded polypeptides from the cytosol. Mammalian YME1L actively attenuates protein import into the matrix in response to stress by degrading Tim17A, a subunit of the TIM23 MIM translocase complex (Rainbolt et al., 2013). In yeast, Ymel provides surveillance for at least two soluble import components, Tim9 and Tim10. These homologous IMS proteins form a heterohexameric chaperone complex that shuttles imported hydrophobic proteins across the aqueous compartment (Koehler et al., 1998; Bolender et al., 2008). Both subunits contain two internal disulfide bonds encoded by $\mathrm{Cx} 3 \mathrm{C}$ motifs, which form in the oxidative IMS environment. Improper formation of these disulfide bonds due to oxidative stress induces degradation of both subunits by Yme1, likely to prevent the accumulation of covalently-linked aggregates (Baker et al., 2012; Spiller et al., 2015). In vitro degradation of purified Tim 9 and Tim 10 by a solubilized Yme1 protease (hexYme1) confirmed an increased degradation rate upon disulfide bond disruption but also indicated that Tim10 is highly preferred as a substrate to Tim9 (Rampello and Glynn, 2017).

In addition to clearing destabilized proteins to prevent the formation of toxic aggregates, the mitochondrial AAA proteases can also target and remove specific proteins as a means of controlling important metabolic pathways. Ups1 and Ups2 are yeast IMS lipid carrier proteins related to the MSF1'/PRELI family conserved across eukaryotes (Dee and Moffat, 2005; Potting et al., 2010). Both proteins form a complex with the small $\mathrm{Cx} 9 \mathrm{C}$ protein, Mdm35, to catalyze the transfer of lipid precursors from the MOM to the MIM to promote synthesis of cardiolipin (CL) and phosphatidylethanolamine (PE) (Sesaki et al., 2006; Osman et al., 2009; Tamura et al., 2009; Potting et al., 2010; Connerth et al., 2012). Lack of CL accumulation in the MIM impairs the function of numerous complexes involved in respiration, mitochondrial fusion, protein translocation, and apotosis (Choi et al., 2007; DeVay et al., 2009; Gebert et al., 2009; Wenz et al., 2009). When complexed to Mdm35, both Ups1 and Ups2 are resistant to proteolysis but are rapidly degraded by Ymel in the absence of the binding partner (Potting et al., 2010). Crystal structures of Ups1-Mdm35 and the homologous mammalian complex, PRELID-TRIAP1, revealed the tertiary structure of Ups1/PRELID is stabilized by complex formation (Miliara et al., 2015; Yu et al., 2015). The degradation of uncomplexed Ups1 and Ups2 allows mitochondria to control the flux of phospholipid precursors across the compartment while the presence of conserved disulfide bonds in Mdm35 suggests that degradation may occur in response to oxidative stress.

\section{Limited Proteolysis and Chaperone Activities}

In recent years, an increasing number of substrates that encounter an alternative proteolytic fate have been identified. Rather than undergoing complete degradation into small peptides, these substrates are partially processed to yield intact fragments that perform further functions. An example of this mode of action that is conserved across yeast and mammals is the maturation of MrpL32, a nuclear-encoded subunit of the mitochondrial ribosome. MrpL32 is imported into the matrix bearing an extensive unstructured $\mathrm{N}$-terminal region that must be removed by m-AAA prior to ribosome assembly (Nolden et al., 2005; Bonn et al., 2011; Woellhaf et al., 2014). More recently identified examples include Atg32, the MOM-anchored regulator of mitophagy in yeast (Kanki et al., 2009; Okamoto et al., 2009). The C-terminal domain of Atg32 projects into the IMS where it is removed by Yme1 to yield a fragment that remains fixed in the membrane. Blocking the proteolytic processing of the Atg32 by Yme1 results in defects in mitophagy (Wang et al., 2013). An example of partial processing observed in mammals is the cleavage of OPA1, a dynamin-related GTPase that regulates mitochondrial dynamics in mammalian cells (Delettre et al., 2000; Praefcke and McMahon, 2004; Lee and Yoon, 2016). Initiation of mitochondrial fission occurs after successive cleavage of OPA1 by the OMA1 and YME1L proteases to generate distinct short isoforms. The balance of mitochondrial fusion and fission is controlled by the relative abundance of the unprocessed long form (L-OPA1) and processed short forms (S-OPA1) (Anand et al., 2014). An analogous regulator found in yeast, Mgm1, does not appear to be cleaved by Yme1 but rather by the MIM rhomboid protease Pcp1 (Herlan et al., 2003; McQuibban et al., 2003).

What is the mechanism that prevents these partially processed substrates from being degraded completely? Maturation of MrpL32 in yeast requires the removal of $71 \mathrm{~N}$-terminal residues and is dependent on the integrity of a cysteine-rich zinc-binding motif located in a tightly folded C-terminal domain (Bonn et al., 2011). In this case, m-AAA appears to processively degrade MrpL32 from the N-terminus until it encounters the highly stable zinc-binding motif, resulting in stalling of the protease and release of the mature ribosomal subunit. Insertion of spacer sequences prior to the folded domain repositioned the $\mathrm{N}$ terminus of the mature protein, implying that cleavage occurs at a site determined by structural rather than sequence constraints. In crystal structures of the assembled mitochondrial ribosome, the distance between the MrpL32 N-terminus and the C-terminal domain is $\sim 35$ residues $(\sim 50 \AA$ ), likely reflecting the distance between the contact site on the outer surface of the protease and the internal proteolytic active sites (Greber et al., 2015). It is an attractive possibility that partial processing of other substrates occurs through a similar mechanism to MrpL32. Atg32 does not contain metal coordination sites but extraction of its transmembrane domain from the MOM could act as a similar barrier to complete degradation, resulting in removal of only the exposed IMS domain. Whereas, extraction from the MIM by Yme1 has been demonstrated conclusively, this model would require the protease to dislocate polypeptides from the MOM with lower efficiency. The presence of the Ymel transmembrane domains or accessory proteins, such as the prohibitins, in MIM but not the MOM may provide an explanation for this difference.

The final mode-of-action displayed by these proteases involve the remodeling of substrates in the absence of proteolysis. Cytochrome c peroxidases (Ccp1) is dislocated from the MIM by m-AAA followed by degradation by a secondary protease, Pcp1 (Tatsuta et al., 2007). In yeast, Yme1 was shown to aid the import of a mammalian polynucleotide phosphorylase into the IMS 
(Rainey et al., 2006). Evidence also exists that i-AAA is capable of chaperone-like activity to prevent formation of aggregates by protein refolding rather than degradation (Leonhard et al., 1999; Schreiner et al., 2012).

\section{SUBSTRATE RECOGNITION}

The studies described above clearly demonstrate that the mitochondrial AAA proteases can act as both general housekeeping enzymes and targeted proteases, processing and degrading specific substrates. Resolving this apparent dichotomy requires understanding the precise mechanisms used to identify and engage substrates. The in vivo degradation by yeast Yme1 of a thermolabile variant of mouse dihydrofolate reductase (mDHFR) fused to the terminus of the integral MIM protein Yme2p generated a number of potential models for substrate recognition (Leonhard et al., 2000). Here, increasing temperature destabilized the solvent accessible mDHFR domain and initiated degradation of the entire fusion protein. The protease could be failing to unfold the folded mDHFR domain at low temperature, sensing the appearance of unstructured polypeptides in proximity to the membrane face, or recognizing specific patterns of residues that only become accessible after domain unfolding at high temperature. Domain swap experiments between i-AAA proteases from Sacchromyces cerevisiae and Neurospora crassa revealed that specificity for certain substrates for could be transplanted, suggesting a mechanism other than sensing folding state (Graef et al., 2007). Moreover, a solubilized human YME1L protease (hexYME1L) was used to demonstrate that simple protein unfolding is not sufficient to initiate degradation and that the protease is capable of unfolding circularly-permuted GFP variants with varying thermodynamic stabilities in vitro, indicating that the enzyme possesses moderate unfolding power (Shi et al., 2016).

Maximal degradation by hexYME1L required substrates to display unstructured terminal tags of 10-20 residues, consistent with in vivo experiments defining a minimal length of 20 residues needed to project from the membrane face to initiate degradation (Leonhard et al., 2000; Shi et al., 2016). Many $\mathrm{AAA}+$ proteases select substrates by recognition of defined sequences, known as degrons (Baker and Sauer, 2006). A survey of model degron sequences identified a phenylalaninerich motif that was preferentially recognized by hexYME1L (Shi et al., 2016). Furthermore, a solubilized yeast hexYme1 protease was used to identify a phenylalanine-rich degradation signal present at the N-terminus of mitochondrial Tim10 (Rampello and Glynn, 2017). This sequence was necessary and sufficient to promote degradation by hexYmel and the presence of similar N-terminal motifs in additional small Tim family members predicted their degradation by the protease. Together, these studies demonstrated unambiguously that iAAA can recognize specific sequences located at accessible termini and opened the possibility that conserved recognition motifs may be found across diverse mitochondrial substrates. Intriguingly, a similar motif was found to target substrates to the bacterial Lon protease (Gur and Sauer, 2008). As with the mitochondrial AAA proteases, Lon has a hybrid function of general surveillance and specific protein degradation. A preference for hydrophobic residues such as phenylalanine, which become exposed after domain unfolding, would allow these proteases to select damaged proteins from among the crowded mitochondrial proteome. The presence of these residues at accessible termini in certain constitutively degraded proteins would then allow both the mitochondrial AAA proteases and Lon to bridge the gap between quality control and targeted proteolysis (Figure 3).

Substrates of AAA + proteases are classically recognized by $\mathrm{N}$-terminal domains found at the apical face of the AAA+ ATPase module or by elements within the central translocating pore (Baker and Sauer, 2006). Substrate binding sites on yeast Ymel have been mapped to conserved helical regions located at distinct positions on the $\mathrm{AAA}+(\mathrm{NH})$ and protease rings (CH) (Graef et al., 2007). Involvement of each binding site is substrate dependent with a more stringent requirement for the $\mathrm{CH}$ sites in the degradation of peripheral membrane proteins. The preference for phenylalanine-rich sequences identified in vitro could imply the presence of similarly hydrophobic substrate binding sites on the enzyme. However, the NH sites of Yme1 contain multiple negatively charged residues, inconsistent with interaction with aromatic side chains. Again, this is reminiscent of bacterial Lon that uses distinct binding sites to recognize highly divergent degron sequences (Gur and Sauer, 2009). Further experiments are required to elucidate the precise mechanisms used by the mitochondrial proteases to capture specific degron sequences.

The identification of multiple substrate binding sites on Yme1 may also provide an explanation for how the mitochondrial

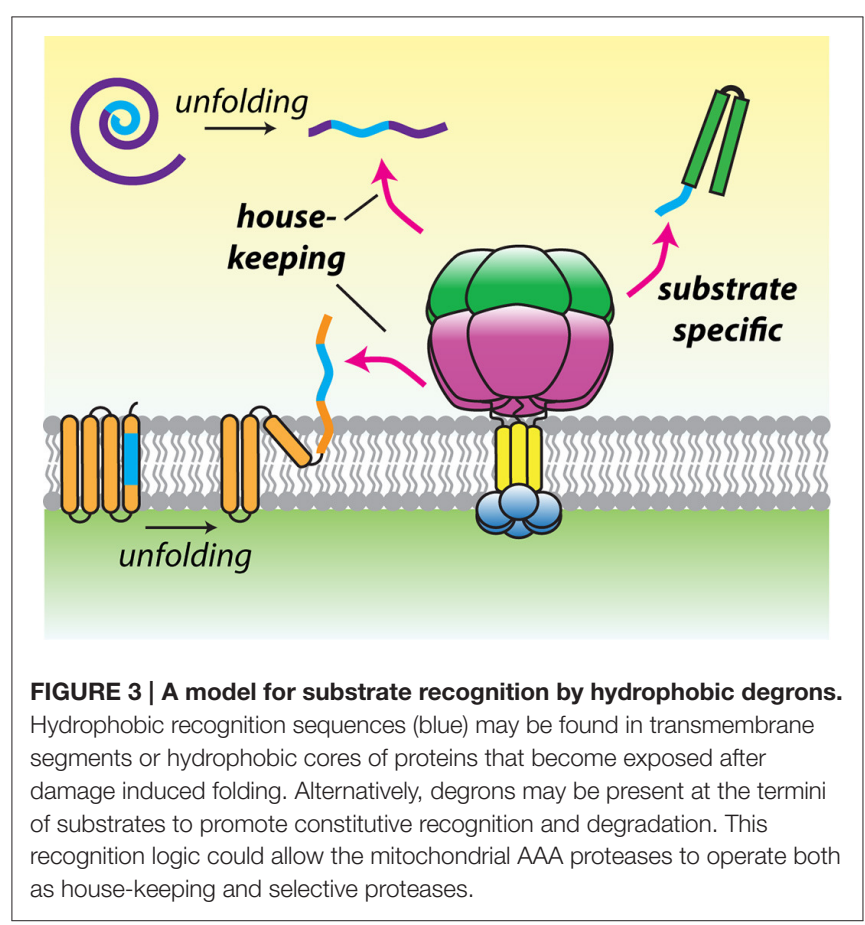


AAA proteases overcome a geometric handicap when degrading soluble and peripheral membrane proteins. The entrance to the central pore of each protease directly faces the bilayer, limiting the opportunity for interaction the pore and extramembrane substrates. Whereas integral membrane proteins can be easily engaged by $\mathrm{NH}$ sites and fed directly into the proteolytic chamber, substrates located far from the membrane face may be held in place by $\mathrm{CH}$ sites to increase their effective concentration close to the translocating pore. To further facilitate substrate engagement, both proteases contain unstructured linkers of typically $20-25$ residues that traverse from TM to the exterior of the AAA+ ring, creating a maximal space between the membrane face and the central pore of $\sim 30-45 \AA$.

Many AAA+ proteases use adaptor proteins to enhance both substrate selectivity and degradation (Levchenko et al., 2000; Dougan et al., 2002a,b). In addition to the prohibitin rings and SPY complex discussed previously, Mgr1 and Mgr3 have been identified as possible adaptors for Ymel in yeast (Dunn et al., 2006, 2008). These MIM anchored proteins form a subcomplex that interacts with Yme1 and are required for efficient binding of unfolded polypeptides that project from the MIM (Dunn et al., 2008). Few substrates that require the action of Mgr1/Mgr3 have been directly detected but Yme1-dependent degradation of Cox2 is severely attenuated by deletion of the putative adaptors (Elliott et al., 2012).

\section{MECHANISMS OF EXTRACTION FROM THE MEMBRANE}

The degradation of integral membrane proteins requires the extraction of transmembrane domains from a favorable phospholipid environment into an unfavorable aqueous compartment. The mechanisms used by the mitochondrial AAA proteases to overcome this barrier remain elusive. Two possible approaches that can be envisioned are: (1) forced dislocation of the transmembrane regions powered by ATP hydrolysis and (2) destabilization of the interactions between substrate transmembrane domains and the bilayer. Many AAA+ proteins translocate proteins across membranes and it is reasonable to assume that similarities exist in their mechanisms of extraction. For example, the degradation of multiple integral membrane proteins by $\mathrm{FtsH}$ has been demonstrated in bacteria (Bittner et al., 2015; Hari and Sauer, 2016). In eukaryotes, Msp1 is a membrane-anchored AAA+ protein that lacks proteolytic activity and extracts improperly localized tail-anchored proteins from the cytosolic face of the MOM (Chen et al., 2014; Okreglak and Walter, 2014). Endoplasmic-reticulum associated degradation (ERAD) requires the translocation of ubiquitinated polypeptides across the ER membrane by a group of proteins involving the p97/Cdc48 motor protein (Wolf and Stolz, 2012; Ruggiano et al., 2014). Recently, the extraction of mitochondrial proteins from the MOM has been demonstrated by cytosolic p97/Cdc48 (Heo et al., 2010; Tanaka et al., 2010). The mechanism of translocation in ERAD is debated but may involve passage through a hydrophobic protein channel (Stein et al., 2014). Similarly, the possibility remains that the transmembrane domains of the mitochondrial proteases form a hydrophobic channel through which polypeptides can pass en route to the central pore.

The force required to mechanically extract transmembrane helices from lipid bilayers of varying composition has been measured between 90 and 200 pN (Oesterhelt et al., 2000; Ganchev et al., 2004). It has been noted that the hydrophobicity of integral MIM proteins is generally lower than those in the bacterial inner membrane or eukaryotic plasma membrane, suggesting a lower force is required for extraction (von Heijne, 1986). A study examining the retention of simple transmembrane sequences in the MIM demonstrated that sequences required $>3: 1$ leucine:alanine residues to escape dislocation from the membrane by m-AAA. Under this scheme, the protease could extract most MIM proteins (Botelho et al., 2013). The central pores of both proteases contain loops bearing the canonical aromatic-hydrophobic (Ar- $\phi$ ) motif that are proposed to deliver the translocating force (Graef and Langer, 2006; Martin et al., 2008). Mutation of the Ar- $\phi$ motif impairs the translocation and degradation but not binding of membrane proteins by Yme1, indicating defects in the power stroke (Graef and Langer, 2006). A rigorous in vitro analysis demonstrated that E. coli $\mathrm{FtsH}$ lacks significant unfolding power and suggested the protease targets already destabilized proteins as a means of selecting damaged substrates (Herman et al., 2003). While hexYME1L is capable of unfolding stable proteins, a comparison with other $\mathrm{AAA}+$ proteases placed the unfolding power between FtsH and robust unfoldases such as ClpXP and Lon (Shi et al., 2016). Possession of an intermediate power stroke may provide the mitochondrial AAA proteases with a pulling force too weak to unfold the C-terminal domain of MrpL32 or fully remove Atg32 from the MOM but sufficient to extract substrates from the MIM.

\section{CONCLUDING REMARKS}

Significant progress has been made in recent years in expanding the repertoire of functions performed by the mitochondrial AAA proteases and understanding how these enzymes select and process substrates. However, the answers to many important questions remain elusive. What are the precise interactions used by these enzymes to recognize and engage protein substrates and do they differ for substrates that undergo different fates? What mechanisms exist in mitochondria to modify protease activity to provide further regulation to the mitochondrial proteome, either in form of environmental changes, allosteric modulators, or cofactors such as adaptor proteins? The recent emergence of degron sequences that target substrates for degradation greatly expands the constellation of potential experiments that can be used to elucidate substrate recognition both in vivo and in vitro. Furthermore, the involvement of both proteases in supramolecular complexes mediated by scaffolding proteins presents a clear avenue to understand how protease activity may be altered by association with other mitochondrial proteins. To date, a lack of structural information has hampered our understanding of the precise mechanisms of the mitochondrial AAA proteases but recent advances in cryoelectron microscopy offer the opportunity 
to visualize these ATP-fueled proteolytic machines at highresolution and gain insight into the molecular details of the degradation process used to preserve the essential functions of mitochondria.

\section{AUTHOR CONTRIBUTIONS}

SG conceived of the topic and wrote the manuscript.

\section{REFERENCES}

Akiyama, Y., and Ito, K. (2000). Roles of multimerization and membrane association in the proteolytic functions of FtsH (HflB). EMBO J. 19, 3888-3895. doi: 10.1093/emboj/19.15.3888

Akiyama, Y., Kihara, A., Mori, H., Ogura, T., and Ito, K. (1998). Roles of the periplasmic domain of Escherichia coli FtsH (HflB) in protein interactions and activity modulation. J. Biol. Chem. 273, 22326-22333. doi: $10.1074 /$ jbc.273.35.22326

Alikhani, N., Berglund, A. K., Engmann, T., Spanning, E., Vogtle, F. N., Pavlov, P., et al. (2011). Targeting capacity and conservation of PreP homologues localization in mitochondria of different species. J. Mol. Biol. 410, 400-410. doi: 10.1016/j.jmb.2011.05.009

Anand, R., Wai, T., Baker, M. J., Kladt, N., Schauss, A. C., Rugarli, E., et al. (2014). The i-AAA protease YME1L and OMA1 cleave OPA1 to balance mitochondrial fusion and fission. J. Cell Biol. 204, 919-929. doi: 10.1083/jcb.2013 08006

Anderson, S., Bankier, A. T., Barrell, B. G., De Bruijn, M. H., Coulson, A. R., Drouin, J., et al. (1981). Sequence and organization of the human mitochondrial genome. Nature 290, 457-465. doi: 10.1038/290457a0

Arlt, H., Tauer, R., Feldmann, H., Neupert, W., and Langer, T. (1996). The YTA10-12 complex, an AAA protease with chaperone-like activity in the inner membrane of mitochondria. Cell 85, 875-885. doi: 10.1016/S0092-8674(00)81271-4

Augustin, S., Gerdes, F., Lee, S., Tsai, F. T., Langer, T., and Tatsuta, T. (2009). An intersubunit signaling network coordinates ATP hydrolysis by m-AAA proteases. Mol. Cell 35, 574-585. doi: 10.1016/j.molcel.2009.07.018

Augustin, S., Nolden, M., Muller, S., Hardt, O., Arnold, I., and Langer, T. (2005). Characterization of peptides released from mitochondria: evidence for constant proteolysis and peptide efflux. J. Biol. Chem. 280, 2691-2699. doi: 10.1074/jbc.M410609200

Baker, M. J., Mooga, V. P., Guiard, B., Langer, T., Ryan, M. T., and Stojanovski, D. (2012). Impaired folding of the mitochondrial small TIM chaperones induces clearance by the i-AAA protease. J. Mol. Biol. 424, 227-239. doi: 10.1016/j.jmb.2012.09.019

Baker, T. A., and Sauer, R. T. (2006). ATP-dependent proteases of bacteria: recognition logic and operating principles. Trends Biochem. Sci. 31, 647-653. doi: 10.1016/j.tibs.2006.10.006

Beckman, K. B., and Ames, B. N. (1998). The free radical theory of aging matures. Physiol. Rev. 78, 547-581.

Bieniossek, C., Niederhauser, B., and Baumann, U. M. (2009). The crystal structure of apo-FtsH reveals domain movements necessary for substrate unfolding and translocation. Proc. Natl. Acad. Sci. U.S.A. 106, 21579-21584. doi: 10.1073/pnas.0910708106

Bittner, L. M., Westphal, K., and Narberhaus, F. (2015). Conditional proteolysis of the membrane protein $\mathrm{YfgM}$ by the FtsH protease depends on a novel N-terminal degron. J. Biol. Chem. 290, 19367-19378. doi: 10.1074/jbc.M115.648550

Bohovych, I., Chan, S. S., and Khalimonchuk, O. (2015). Mitochondrial protein quality control: the mechanisms guarding mitochondrial health. Antioxid. Redox Signal. 22, 977-994. doi: 10.1089/ars.2014.6199

Bolender, N., Sickmann, A., Wagner, R., Meisinger, C., and Pfanner, N. (2008). Multiple pathways for sorting mitochondrial precursor proteins. EMBO Rep. 9, 42-49. doi: 10.1038/sj.embor.7401126

\section{FUNDING}

Work in the author's lab is funded by NIH grant R01 GM115898.

\section{ACKNOWLEDGMENTS}

I thank Bojian Ding and Anthony Rampello for helpful discussions

Bonn, F., Tatsuta, T., Petrungaro, C., Riemer, J., and Langer, T. (2011). Presequence-dependent folding ensures MrpL32 processing by the m-AAA protease in mitochondria. EMBO J. 30, 2545-2556. doi: 10.1038/emboj.2011.169

Botelho, S. C., Tatsuta, T., Von Heijne, G., and Kim, H. (2013). Dislocation by the $\mathrm{m}$-AAA protease increases the threshold hydrophobicity for retention of transmembrane helices in the inner membrane of yeast mitochondria. J. Biol. Chem. 288, 4792-4798. doi: 10.1074/jbc.M112.430892

Bulteau, A. L., and Bayot, A. (2011). Mitochondrial proteases and cancer. Biochim. Biophys. Acta 1807, 595-601. doi: 10.1016/j.bbabio.2010.12.011

Cagnoli, C., Stevanin, G., Brussino, A., Barberis, M., Mancini, C., Margolis, R. L., et al. (2010). Missense mutations in the AFG3L2 proteolytic domain account for approximately $1.5 \%$ of European autosomal dominant cerebellar ataxias. Hum. Mutat. 31, 1117-1124. doi: 10.1002/humu.21342

Calvo, S. E., Clauser, K. R., and Mootha, V. K. (2016). MitoCarta2.0: an updated inventory of mammalian mitochondrial proteins. Nucleic Acids Res. 44, D1251D1257. doi: 10.1093/nar/gkv1003

Campbell, C. L., Tanaka, N., White, K. H., and Thorsness, P. E. (1994). Mitochondrial morphological and functional defects in yeast caused by yme1 are suppressed by mutation of a $26 \mathrm{~S}$ protease subunit homologue. Mol. Biol. Cell 5, 899-905. doi: 10.1091/mbc.5.8.899

Cha, S. S., An, Y. J., Lee, C. R., Lee, H. S., Kim, Y. G., Kim, S. J., et al. (2010). Crystal structure of Lon protease: molecular architecture of gated entry to a sequestered degradation chamber. EMBO J. 29, 3520-3530. doi: 10.1038/emboj.2010.226

Chan, D. C. (2006). Mitochondria: dynamic organelles in disease, aging, and development. Cell 125, 1241-1252. doi: 10.1016/j.cell.2006.06.010

Chen, Y. C., Umanah, G. K., Dephoure, N., Andrabi, S. A., Gygi, S. P., Dawson, T. M., et al. (2014). Msp1/ATAD1 maintains mitochondrial function by facilitating the degradation of mislocalized tail-anchored proteins. EMBO J. 33, 1548-1564. doi: 10.15252/embj.201487943

Choi, S. Y., Gonzalvez, F., Jenkins, G. M., Slomianny, C., Chretien, D., Arnoult, D., et al. (2007). Cardiolipin deficiency releases cytochrome c from the inner mitochondrial membrane and accelerates stimuli-elicited apoptosis. Cell Death Differ. 14, 597-606. doi: 10.1038/sj.cdd.4402020

Connerth, M., Tatsuta, T., Haag, M., Klecker, T., Westermann, B., and Langer, T. (2012). Intramitochondrial transport of phosphatidic acid in yeast by a lipid transfer protein. Science 338, 815-818. doi: 10.1126/science.12 25625

Corydon, T. J., Wilsbech, M., Jespersgaard, C., Andresen, B. S., Borglum, A. D., Pedersen, S., et al. (2000). Human and mouse mitochondrial orthologs of bacterial ClpX. Mamm. Genome 11, 899-905. doi: 10.1007/s003350010173

D'Andrea, L. D., and Regan, L. (2003). TPR proteins: the versatile helix. Trends Biochem. Sci. 28, 655-662. doi: 10.1016/j.tibs.2003.10.007

Dee, C. T., and Moffat, K. G. (2005). A novel family of mitochondrial proteins is represented by the Drosophila genes slmo, preli-like and real-time. Dev. Genes Evol. 215, 248-254. doi: 10.1007/s00427-005-0470-4

Delettre, C., Lenaers, G., Griffoin, J. M., Gigarel, N., Lorenzo, C., Belenguer, P., et al. (2000). Nuclear gene OPA1, encoding a mitochondrial dynaminrelated protein, is mutated in dominant optic atrophy. Nat. Genet. 26, 207-210. doi: $10.1038 / 79936$

DeVay, R. M., Dominguez-Ramirez, L., Lackner, L. L., Hoppins, S., Stahlberg, H., and Nunnari, J. (2009). Coassembly of Mgm1 isoforms requires cardiolipin and mediates mitochondrial inner membrane fusion. J. Cell Biol. 186, 793-803. doi: $10.1083 /$ jcb. 200906098 
Di Bella, D., Lazzaro, F., Brusco, A., Plumari, M., Battaglia, G., Pastore, A., et al. (2010). Mutations in the mitochondrial protease gene AFG3L2 cause dominant hereditary ataxia SCA28. Nat. Genet. 42, 313-321. doi: 10.1038/ng.544

Diaz, F., and Moraes, C. T. (2008). Mitochondrial biogenesis and turnover. Cell Calcium 44, 24-35. doi: 10.1016/j.ceca.2007.12.004

Dougan, D. A., Mogk, A., Zeth, K., Turgay, K., and Bukau, B. (2002a). AAA+ proteins and substrate recognition, it all depends on their partner in crime. FEBS Lett. 529, 6-10. doi: 10.1016/S0014-5793(02)03179-4

Dougan, D. A., Reid, B. G., Horwich, A. L., and Bukau, B. (2002b). ClpS, a substrate modulator of the ClpAP machine. Mol. Cell 9, 673-683. doi: 10.1016/S1097-2765(02)00485-9

Dunn, C. D., Lee, M. S., Spencer, F. A., and Jensen, R. E. (2006). A genomewide screen for petite-negative yeast strains yields a new subunit of the i-AAA protease complex. Mol. Biol. Cell 17, 213-226. doi: 10.1091/mbc.E05-06-0585

Dunn, C. D., Tamura, Y., Sesaki, H., and Jensen, R. E. (2008). Mgr3p and Mgrlp are adaptors for the mitochondrial i-AAA protease complex. Mol. Biol. Cell 19, 5387-5397. doi: 10.1091/mbc.E08-01-0103

Elliott, L. E., Saracco, S. A., and Fox, T. D. (2012). Multiple roles of the Cox20 chaperone in assembly of Saccharomyces cerevisiae cytochrome c oxidase. Genetics 190, 559-567. doi: 10.1534/genetics.111.135665

Frickey, T., and Lupas, A. N. (2004). Phylogenetic analysis of AAA proteins. J. Struct. Biol. 146, 2-10. doi: 10.1016/j.jsb.2003.11.020

Ganchev, D. N., Rijkers, D. T., Snel, M. M., Killian, J. A., and De Kruijff, B. (2004). Strength of integration of transmembrane alpha-helical peptides in lipid bilayers as determined by atomic force spectroscopy. Biochemistry 43, 14987-14993. doi: 10.1021/bi048372y

Gebert, N., Joshi, A. S., Kutik, S., Becker, T., McKenzie, M., Guan, X. L., et al. (2009). Mitochondrial cardiolipin involved in outer-membrane protein biogenesis: implications for Barth syndrome. Curr. Biol. 19, 2133-2139. doi: $10.1016 /$ j.cub.2009.10.074

Gerdes, F., Tatsuta, T., and Langer, T. (2012). Mitochondrial AAA proteasestowards a molecular understanding of membrane-bound proteolytic machines. Biochim. Biophys. Acta 1823, 49-55. doi: 10.1016/j.bbamcr.2011.09.015

Graef, M., and Langer, T. (2006). Substrate specific consequences of central pore mutations in the i-AAA protease Yme1 on substrate engagement. J. Struct. Biol. 156, 101-108. doi: 10.1016/j.jsb.2006.01.009

Graef, M., Seewald, G., and Langer, T. (2007). Substrate recognition by AAA+ ATPases: distinct substrate binding modes in ATP-dependent protease Yme1 of the mitochondrial intermembrane space. Mol. Cell. Biol. 27, 2476-2485. doi: 10.1128/MCB.01721-06

Greber, B. J., Bieri, P., Leibundgut, M., Leitner, A., Aebersold, R., Boehringer, D., et al. (2015). Ribosome. The complete structure of the 55S mammalian mitochondrial ribosome. Science 348, 303-308. doi: 10.1126/science.aaa3872

Gur, E., and Sauer, R. T. (2008). Recognition of misfolded proteins by Lon, a AAA(+) protease. Genes Dev. 22, 2267-2277. doi: 10.1101/gad.16 70908

Gur, E., and Sauer, R. T. (2009). Degrons in protein substrates program the speed and operating efficiency of the AAA+ Lon proteolytic machine. Proc. Natl. Acad. Sci. U.S.A. 106, 18503-18508. doi: 10.1073/pnas.0910392106

Hanson, P. I., and Whiteheart, S. W. (2005). AAA+ proteins: have engine, will work. Nat. Rev. Mol. Cell Biol. 6, 519-529. doi: 10.1038/nrm1684

Hari, S. B., and Sauer, R. T. (2016). The AAA + FtsH protease degrades an ssrAtagged model protein in the inner membrane of Escherichia coli. Biochemistry 55, 5649-5652. doi: 10.1021/acs.biochem.6b00920

Heo, J. M., Livnat-Levanon, N., Taylor, E. B., Jones, K. T., Dephoure, N., Ring, J., et al. (2010). A stress-responsive system for mitochondrial protein degradation. Mol. Cell 40, 465-480. doi: 10.1016/j.molcel.2010.10.021

Herlan, M., Vogel, F., Bornhovd, C., Neupert, W., and Reichert, A. S. (2003). Processing of Mgm1 by the rhomboid-type protease Pcp1 is required for maintenance of mitochondrial morphology and of mitochondrial DNA. J. Biol. Chem. 278, 27781-27788. doi: 10.1074/jbc.M211311200

Herman, C., Prakash, S., Lu, C. Z., Matouschek, A., and Gross, C. A. (2003). Lack of a robust unfoldase activity confers a unique level of substrate specificity to the universal AAA protease FtsH. Mol. Cell 11, 659-669. doi: 10.1016/S1097-2765(03)00068-6

Kanki, T., Wang, K., Cao, Y., Baba, M., and Klionsky, D. J. (2009). Atg32 is a mitochondrial protein that confers selectivity during mitophagy. Dev. Cell 17, 98-109. doi: 10.1016/j.devcel.2009.06.014
Kardon, J. R., Yien, Y. Y., Huston, N. C., Branco, D. S., Hildick-Smith, G. J., Rhee, K. Y., et al. (2015). Mitochondrial ClpX activates a key enzyme for heme biosynthesis and erythropoiesis. Cell 161, 858-867. doi: 10.1016/j.cell.2015.04.017

Karlberg, T., van den Berg, S., Hammarstrom, M., Sagemark, J., Johansson, I., Holmberg-Schiavone, L., et al. (2009). Crystal structure of the ATPase domain of the human AAA+ protein paraplegin/SPG7. PLoS ONE 4:e6975. doi: 10.1371/journal.pone.0006975

Kaser, M., Kambacheld, M., Kisters-Woike, B., and Langer, T. (2003). Oma1, a novel membrane-bound metallopeptidase in mitochondria with activities overlapping with the m-AAA protease. J. Biol. Chem. 278, 46414-46423. doi: 10.1074/jbc.M305584200

Kicia, M., Gola, E. M., and Janska, H. (2010). Mitochondrial protease AtFtsH4 protects ageing Arabidopsis rosettes against oxidative damage under short-day photoperiod. Plant Signal. Behav. 5, 126-128. doi: 10.4161/psb.5.2.10303

Kihara, A., Akiyama, Y., and Ito, K. (1996). A protease complex in the Escherichia coli plasma membrane: HflKC (HflA) forms a complex with FtsH (HflB), regulating its proteolytic activity against SecY. EMBO J. 15, 6122-6131.

Kihara, A., Akiyama, Y., and Ito, K. (1997). Host regulation of lysogenic decision in bacteriophage lambda: transmembrane modulation of $\mathrm{FtsH}$ (HflB), the cII degrading protease, by HflKC (HflA). Proc. Natl. Acad. Sci. U.S.A. 94, 5544-5549. doi: 10.1073/pnas.94.11.5544

Koehler, C. M., Jarosch, E., Tokatlidis, K., Schmid, K., Schweyen, R. J., and Schatz, G. (1998). Import of mitochondrial carriers mediated by essential proteins of the intermembrane space. Science 279, 369-373. doi: 10.1126/science.279.5349.369

Konig, T., Troder, S. E., Bakka, K., Korwitz, A., Richter-Dennerlein, R., Lampe, P. A., et al. (2016). The m-AAA protease associated with neurodegeneration limits MCU activity in mitochondria. Mol. Cell 64, 148-162. doi: 10.1016/j.molcel.2016.08.020

Koppen, M., and Langer, T. (2007). Protein degradation within mitochondria: versatile activities of AAA proteases and other peptidases. Crit. Rev. Biochem. Mol. Biol. 42, 221-242. doi: 10.1080/104092307013 80452

Koppen, M., Metodiev, M. D., Casari, G., Rugarli, E. I., and Langer, T. (2007) Variable and tissue-specific subunit composition of mitochondrial m-AAA protease complexes linked to hereditary spastic paraplegia. Mol. Cell. Biol. 27, 758-767. doi: 10.1128/MCB.01470-06

Korbel, D., Wurth, S., Kaser, M., and Langer, T. (2004). Membrane protein turnover by the m-AAA protease in mitochondria depends on the transmembrane domains of its subunits. EMBO Rep. 5, 698-703. doi: 10.1038/sj.embor.7400186

Lee, H., and Yoon, Y. (2016). Mitochondrial fission and fusion. Biochem. Soc. Trans. 44, 1725-1735. doi: 10.1042/BST20160129

Lee, S., Augustin, S., Tatsuta, T., Gerdes, F., Langer, T., and Tsai, F. T. (2011) Electron cryomicroscopy structure of a membrane-anchored mitochondrial AAA protease. J. Biol. Chem. 286, 4404-4411. doi: 10.1074/jbc.M110.158741

Leonhard, K., Guiard, B., Pellecchia, G., Tzagoloff, A., Neupert, W., and Langer, T. (2000). Membrane protein degradation by AAA proteases in mitochondria: extraction of substrates from either membrane surface. Mol. Cell 5, 629-638. doi: 10.1016/S1097-2765(00)80242-7

Leonhard, K., Herrmann, J. M., Stuart, R. A., Mannhaupt, G., Neupert, W., and Langer, T. (1996). AAA proteases with catalytic sites on opposite membrane surfaces comprise a proteolytic system for the ATP-dependent degradation of inner membrane proteins in mitochondria. EMBO J. 15, 4218-4229.

Leonhard, K., Stiegler, A., Neupert, W., and Langer, T. (1999). Chaperone-like activity of the AAA domain of the yeast Yme1 AAA protease. Nature 398, 348-351. doi: 10.1038/18704

Leonhardt, S. A., Fearson, K., Danese, P. N., and Mason, T. L. (1993). HSP78 encodes a yeast mitochondrial heat shock protein in the Clp family of ATP-dependent proteases. Mol. Cell. Biol. 13, 6304-6313. doi: 10.1128/MCB.13.10.6304

Levchenko, I., Seidel, M., Sauer, R. T., and Baker, T. A. (2000). A specificityenhancing factor for the ClpXP degradation machine. Science 289, 2354-2356. doi: 10.1126 /science.289.5488.2354

Levytskyy, R. M., Germany, E. M., and Khalimonchuk, O. (2016). Mitochondrial quality control proteases in neuronal welfare. J. Neuroimmune Pharmacol. 11, 629-644. doi: 10.1007/s11481-016-9683-8 
Lobbe, A. M., Kang, J. S., Hilker, R., Hackstein, H., Muller, U., and Nolte, D. (2014). A novel missense mutation in AFG3L2 associated with late onset and slow progression of spinocerebellar ataxia type 28. J. Mol. Neurosci. 52, 493-496. doi: 10.1007/s12031-013-0187-1

Maltecca, F., Magnoni, R., Cerri, F., Cox, G. A., Quattrini, A., and Casari, G. (2009). Haploinsufficiency of AFG3L2, the gene responsible for spinocerebellar ataxia type 28, causes mitochondria-mediated Purkinje cell dark degeneration. J. Neurosci. 29, 9244-9254. doi: 10.1523/JNEUROSCI.1532-09.2009

Mariotti, C., Brusco, A., Di Bella, D., Cagnoli, C., Seri, M., Gellera, C., et al. (2008). Spinocerebellar ataxia type 28: a novel autosomal dominant cerebellar ataxia characterized by slow progression and ophthalmoparesis. Cerebellum 7 , 184-188. doi: 10.1007/s12311-008-0053-9

Martin, A., Baker, T. A., and Sauer, R. T. (2008). Diverse pore loops of the AAA+ ClpX machine mediate unassisted and adaptor-dependent recognition of ssrAtagged substrates. Mol. Cell 29, 441-450. doi: 10.1016/j.molcel.2008.02.002

McBride, H. M., Neuspiel, M., and Wasiak, S. (2006). Mitochondria: more than just a powerhouse. Curr. Biol. 16, R551-R560. doi: 10.1016/j.cub.2006.06.054

McQuibban, G. A., Saurya, S., and Freeman, M. (2003). Mitochondrial membrane remodelling regulated by a conserved rhomboid protease. Nature $423,537-541$. doi: 10.1038 /nature01633

Merkwirth, C., and Langer, T. (2009). Prohibitin function within mitochondria: essential roles for cell proliferation and cristae morphogenesis. Biochim. Biophys. Acta 1793, 27-32. doi: 10.1016/j.bbamcr.2008.05.013

Merkwirth, C., Dargazanli, S., Tatsuta, T., Geimer, S., Lower, B., Wunderlich, F. T., et al. (2008). Prohibitins control cell proliferation and apoptosis by regulating OPA1-dependent cristae morphogenesis in mitochondria. Genes Dev. 22, 476-488. doi: 10.1101/gad.460708

Miliara, X., Garnett, J. A., Tatsuta, T., Abid Ali, F., Baldie, H., Perez-Dorado, I., et al. (2015). Structural insight into the TRIAP1/PRELI-like domain family of mitochondrial phospholipid transfer complexes. EMBO Rep. 16, 824-835. doi: 10.15252/embr.201540229

Nakai, T., Yasuhara, T., Fujiki, Y., and Ohashi, A. (1995). Multiple genes, including a member of the AAA family, are essential for degradation of unassembled subunit 2 of cytochrome c oxidase in yeast mitochondria. Mol. Cell. Biol. 15, 4441-4452. doi: 10.1128/MCB.15.8.4441

Neupert, W., and Herrmann, J. M. (2007). Translocation of proteins into mitochondria. Annu. Rev. Biochem. 76, 723-749. doi: 10.1146/annurev. biochem.76.052705.163409

Nolden, M., Ehses, S., Koppen, M., Bernacchia, A., Rugarli, E. I., and Langer, T. (2005). The m-AAA protease defective in hereditary spastic paraplegia controls ribosome assembly in mitochondria. Cell 123, 277-289. doi: 10.1016/j.cell.2005.08.003

Oesterhelt, F., Oesterhelt, D., Pfeiffer, M., Engel, A., Gaub, H. E., and Muller, D. J. (2000). Unfolding pathways of individual bacteriorhodopsins. Science 288, 143-146. doi: 10.1126/science.288.5463.143

Okamoto, K., Kondo-Okamoto, N., and Ohsumi, Y. (2009). Mitochondriaanchored receptor Atg32 mediates degradation of mitochondria via selective autophagy. Dev. Cell 17, 87-97. doi: 10.1016/j.devcel.2009.06.013

Okreglak, V., and Walter, P. (2014). The conserved AAA-ATPase Msp1 confers organelle specificity to tail-anchored proteins. Proc. Natl. Acad. Sci. U.S.A. 111, 8019-8024. doi: 10.1073/pnas.1405755111

Osman, C., Haag, M., Potting, C., Rodenfels, J., Dip, P. V., Wieland, F. T., et al. (2009). The genetic interactome of prohibitins: coordinated control of cardiolipin and phosphatidylethanolamine by conserved regulators in mitochondria. J. Cell Biol. 184, 583-596. doi: 10.1083/jcb.200810189

Pettersen, E. F., Goddard, T. D., Huang, C. C., Couch, G. S., Greenblatt, D. M., Meng, E. C., et al. (2004). UCSF Chimera-a visualization system for exploratory research and analysis. J. Comput. Chem. 25, 1605-1612. doi: 10.1002/jcc. 20084

Pierson, T. M., Adams, D., Bonn, F., Martinelli, P., Cherukuri, P. F., Teer, J. K., et al. (2011). Whole-exome sequencing identifies homozygous AFG3L2 mutations in a spastic ataxia-neuropathy syndrome linked to mitochondrial m-AAA proteases. PLoS Genet. 7:e10 02325. doi: 10.1371/journal.pgen. 1002325

Potting, C., Wilmes, C., Engmann, T., Osman, C., and Langer, T. (2010). Regulation of mitochondrial phospholipids by Ups1/PRELI-like proteins depends on proteolysis and Mdm35. EMBO J. 29, 2888-2898. doi: $10.1038 /$ emboj.2010.169
Praefcke, G. J., and McMahon, H. T. (2004). The dynamin superfamily: universal membrane tubulation and fission molecules? Nat. Rev. Mol. Cell Biol. 5, 133-147. doi: $10.1038 / \mathrm{nrm} 1313$

Qu, J., Wu, C. K., Zuzuarregui, J. R., and Hohler, A. D. (2015). A novel AFG3L2 mutation in a Somalian patient with spinocerebellar ataxia type 28. J. Neurol. Sci. 358, 530-531. doi: 10.1016/j.jns.2015.10.003

Quiros, P. M., Langer, T., and Lopez-Otin, C. (2015). New roles for mitochondrial proteases in health, ageing and disease. Nat. Rev. Mol. Cell Biol. 16, 345-359. doi: $10.1038 / \mathrm{nrm} 3984$

Rainbolt, T. K., Atanassova, N., Genereux, J. C., and Wiseman, R. L. (2013). Stress-regulated translational attenuation adapts mitochondrial protein import through Tim17A degradation. Cell Metab. 18, 908-919. doi: 10.1016/j.cmet.2013.11.006

Rainbolt, T. K., Lebeau, J., Puchades, C., and Wiseman, R. L. (2016). Reciprocal degradation of YME1L and OMA1 adapts mitochondrial proteolytic activity during stress. Cell Rep. 14, 2041-2049. doi: 10.1016/j.celrep.2016.02.011

Rainbolt, T. K., Saunders, J. M., and Wiseman, R. L. (2014). Stress-responsive regulation of mitochondria through the ER unfolded protein response. Trends Endocrinol. Metab. 25, 528-537. doi: 10.1016/j.tem.2014.06.007

Rainbolt, T. K., Saunders, J. M., and Wiseman, R. L. (2015). YME1L degradation reduces mitochondrial proteolytic capacity during oxidative stress. EMBO Rep. 16, 97-106. doi: 10.15252/embr.201438976

Rainey, R. N., Glavin, J. D., Chen, H. W., French, S. W., Teitell, M. A., and Koehler, C. M. (2006). A new function in translocation for the mitochondrial i-AAA protease Yme1: import of polynucleotide phosphorylase into the intermembrane space. Mol. Cell. Biol. 26, 8488-8497. doi: 10.1128/MCB.01006-06

Ramelot, T. A., Yang, Y., Sahu, I. D., Lee, H. W., Xiao, R., Lorigan, G. A., et al. (2013). NMR structure and MD simulations of the AAA protease intermembrane space domain indicates peripheral membrane localization within the hexaoligomer. FEBS Lett. 587, 3522-3528. doi: 10.1016/j.febslet.2013.09.009

Rampello, A. J., and Glynn, S. E. (2017). Identification of a degradation signal sequence within substrates of the mitochondrial i-AAA protease. J. Mol. Biol. 429, 873-885. doi: 10.1016/j.jmb.2017.02.009

Rawlings, N. D., and Barrett, A. J. (1995). Evolutionary families of metallopeptidases. Methods Enzymol. 248, 183-228. doi: 10.1016/ 0076-6879(95)48015-3

Rhee, H. W., Zou, P., Udeshi, N. D., Martell, J. D., Mootha, V. K., Carr, S. A., et al. (2013). Proteomic mapping of mitochondria in living cells via spatially restricted enzymatic tagging. Science 339, 1328-1331. doi: $10.1126 /$ science. 1230593

Ruan, L., Zhou, C., Jin, E., Kucharavy, A., Zhang, Y., Wen, Z., et al. (2017). Cytosolic proteostasis through importing of misfolded proteins into mitochondria. Nature 543, 443-446. doi: 10.1038/nature21695

Rugarli, E. I., and Langer, T. (2012). Mitochondrial quality control: a matter of life and death for neurons. EMBO J. 31, 1336-1349. doi: 10.1038/emboj.2012.38

Ruggiano, A., Foresti, O., and Carvalho, P. (2014). Quality control: ER-associated degradation: protein quality control and beyond. J. Cell Biol. 204, 869-879. doi: $10.1083 /$ jcb. 201312042

Scharfenberg, F., Serek-Heuberger, J., Coles, M., Hartmann, M. D., Habeck, M., Martin, J., et al. (2015). Structure and evolution of $\mathrm{N}$-domains in AAA metalloproteases. J. Mol. Biol. 427, 910-923. doi: 10.1016/j.jmb.2014.12.024

Schreiner, B., Westerburg, H., Forne, I., Imhof, A., Neupert, W., and Mokranjac, D. (2012). Role of the AAA protease Ymel in folding of proteins in the intermembrane space of mitochondria. Mol. Biol. Cell 23, 4335-4346. doi: 10.1091/mbc.E12-05-0420

Sesaki, H., Dunn, C. D., Iijima, M., Shepard, K. A., Yaffe, M. P., Machamer, C. E., et al. (2006). Upslp, a conserved intermembrane space protein, regulates mitochondrial shape and alternative topogenesis of Mgm1p. J. Cell Biol. 173, 651-658. doi: $10.1083 /$ jcb. 200603092

Shi, H., Rampello, A. J., and Glynn, S. E. (2016). Engineered AAA+ proteases reveal principles of proteolysis at the mitochondrial inner membrane. Nat. Commun. 7:13301. doi: 10.1038/ncomms13301

Sickmann, A., Reinders, J., Wagner, Y., Joppich, C., Zahedi, R., Meyer, H. E., et al. (2003). The proteome of Saccharomyces cerevisiae mitochondria Proc. Natl. Acad. Sci. U.S.A. 100, 13207-13212. doi: 10.1073/pnas.21353 85100 
Smakowska, E., Czarna, M., and Janska, H. (2014). Mitochondrial ATP-dependent proteases in protection against accumulation of carbonylated proteins. Mitochondrion 19(Pt B), 245-251. doi: 10.1016/j.mito.2014.03.005

Spiller, M. P., Guo, L., Wang, Q., Tran, P., and Lu, H. (2015). Mitochondrial Tim9 protects Tim10 from degradation by the protease Yme1. Biosci. Rep. 35, e00193. doi: 10.1042/BSR20150038

Steglich, G., Neupert, W., and Langer, T. (1999). Prohibitins regulate membrane protein degradation by the m-AAA protease in mitochondria. Mol. Cell. Biol. 19, 3435-3442. doi: 10.1128/MCB.19.5.3435

Stein, A., Ruggiano, A., Carvalho, P., and Rapoport, T. A. (2014). Key steps in ERAD of luminal ER proteins reconstituted with purified components. Cell 158, 1375-1388. doi: 10.1016/j.cell.2014.07.050

Stiburek, L., Cesnekova, J., Kostkova, O., Fornuskova, D., Vinsova, K., Wenchich, L., et al. (2012). YME1L controls the accumulation of respiratory chain subunits and is required for apoptotic resistance, cristae morphogenesis, and cell proliferation. Mol. Biol. Cell 23, 1010-1023. doi: 10.1091/mbc.E1108-0674

Su, S. C., Lin, C. C., Tai, H. C., Chang, M. Y., Ho, M. R., Babu, C. S., et al. (2016). Structural basis for the magnesium-dependent activation and hexamerization of the lon AAA+ protease. Structure 24,676-686. doi: 10.1016/j.str.2016.03.003

Suno, R., Niwa, H., Tsuchiya, D., Zhang, X., Yoshida, M., and Morikawa, K. (2006). Structure of the whole cytosolic region of ATP-dependent protease FtsH. Mol. Cell 22, 575-585. doi: 10.1016/j.molcel.2006.04.020

Suzuki, C. K., Suda, K., Wang, N., and Schatz, G. (1994). Requirement for the yeast gene LON in intramitochondrial proteolysis and maintenance of respiration. Science 264, 273-276. doi: 10.1126/science.8146662

Svenstrup, K., Nielsen, T. T., Aidt, F., Rostgaard, N., Duno, M., Wibrand, F., et al. (2017). SCA28: novel mutation in the AFG3L2 proteolytic domain causes a mild cerebellar syndrome with selective type-1 muscle fiber atrophy. Cerebellum 16, 62-67. doi: 10.1007/s12311-016-0765-1

Tamura, Y., Endo, T., Iijima, M., and Sesaki, H. (2009). Ups1p and Ups2p antagonistically regulate cardiolipin metabolism in mitochondria. J. Cell Biol. 185, 1029-1045. doi: 10.1083/jcb.200812018

Tanaka, A., Cleland, M. M., Xu, S., Narendra, D. P., Suen, D. F., Karbowski, M., et al. (2010). Proteasome and p97 mediate mitophagy and degradation of mitofusins induced by Parkin. J. Cell Biol. 191, 1367-1380. doi: $10.1083 /$ jcb. 201007013

Tatsuta, T., Augustin, S., Nolden, M., Friedrichs, B., and Langer, T. (2007). $\mathrm{m}$-AAA protease-driven membrane dislocation allows intramembrane cleavage by rhomboid in mitochondria. EMBO J. 26, 325-335. doi: 10.1038/sj.emboj.7601514

Tatsuta, T., and Langer, T. (2009). AAA proteases in mitochondria: diverse functions of membrane-bound proteolytic machines. Res. Microbiol. 160, 711-717. doi: 10.1016/j.resmic.2009.09.005

Tatsuta, T., Model, K., and Langer, T. (2005). Formation of membrane-bound ring complexes by prohibitins in mitochondria. Mol. Biol. Cell 16, 248-259. doi: 10.1091/mbc.E04-09-0807

Truscott, K. N., Lowth, B. R., Strack, P. R., and Dougan, D. A. (2010). Diverse functions of mitochondrial AAA + proteins: protein activation, disaggregation, and degradation. Biochem. Cell Biol. 88, 97-108. doi: 10.1139/O09-167

Tzagoloff, A., Yue, J., Jang, J., and Paul, M. F. (1994). A new member of a family of ATPases is essential for assembly of mitochondrial respiratory chain and ATP synthetase complexes in Saccharomyces cerevisiae. J. Biol. Chem. 269, 26144-26151.
Ugarte, N., Petropoulos, I., and Friguet, B. (2010). Oxidized mitochondrial protein degradation and repair in aging and oxidative stress. Antioxid. Redox Signal. 13, 539-549. doi: 10.1089/ars.2009.2998

van Dyck, L., Dembowski, M., Neupert, W., and Langer, T. (1998). Mcxlp, a ClpX homologue in mitochondria of Saccharomyces cerevisiae. FEBS Lett. 438, 250-254. doi: 10.1016/S0014-5793(98)01310-6

van Dyck, L., Pearce, D. A., and Sherman, F. (1994). PIM1 encodes a mitochondrial ATP-dependent protease that is required for mitochondrial function in the yeast Saccharomyces cerevisiae. J. Biol. Chem. 269, 238-242.

von Heijne, G. (1986). Why mitochondria need a genome. FEBS Lett. 198, 1-4. doi: 10.1016/0014-5793(86)81172-3

Wai, T., Saita, S., Nolte, H., Muller, S., Konig, T., Richter-Dennerlein, R., et al. (2016). The membrane scaffold SLP2 anchors a proteolytic hub in mitochondria containing PARL and the i-AAA protease YME1L. EMBO Rep. 17, 1844-1856. doi: 10.15252/embr.201642698

Wang, K., Jin, M., Liu, X., and Klionsky, D. J. (2013). Proteolytic processing of Atg32 by the mitochondrial i-AAA protease Yme1 regulates mitophagy. Autophagy 9, 1828-1836. doi: 10.4161/auto.26281

Wang, N., Gottesman, S., Willingham, M. C., Gottesman, M. M., and Maurizi, M. R. (1993). A human mitochondrial ATP-dependent protease that is highly homologous to bacterial Lon protease. Proc. Natl. Acad. Sci. U.S.A. 90, 11247-11251. doi: 10.1073/pnas.90.23.11247

Weber, E. R., Rooks, R. S., Shafer, K. S., Chase, J. W., and Thorsness, P. E. (1995) Mutations in the mitochondrial ATP synthase gamma subunit suppress a slowgrowth phenotype of ymel yeast lacking mitochondrial DNA. Genetics 140, 435-442.

Wenz, T., Hielscher, R., Hellwig, P., Schagger, H., Richers, S., and Hunte, C. (2009). Role of phospholipids in respiratory cytochrome bc(1) complex catalysis and supercomplex formation. Biochim. Biophys. Acta 1787, 609-616. doi: 10.1016/j.bbabio.2009.02.012

Woellhaf, M. W., Hansen, K. G., Garth, C., and Herrmann, J. M. (2014). Import of ribosomal proteins into yeast mitochondria. Biochem. Cell Biol. 92, 489-498. doi: 10.1139/bcb-2014-0029

Wolf, D. H., and Stolz, A. (2012). The Cdc48 machine in endoplasmic reticulum associated protein degradation. Biochim. Biophys. Acta 1823, 117-124. doi: 10.1016/j.bbamcr.2011.09.002

Yu, F., He, F., Yao, H., Wang, C., Wang, J., Li, J., et al. (2015). Structural basis of intramitochondrial phosphatidic acid transport mediated by Ups1-Mdm35 complex. EMBO Rep. 16, 813-823. doi: 10.15252/embr.201540137

Zuhlke, C., Mikat, B., Timmann, D., Wieczorek, D., Gillessen-Kaesbach, G., and Burk, K. (2015). Spinocerebellar ataxia 28: a novel AFG3L2 mutation in a German family with young onset, slow progression and saccadic slowing. Cerebellum Ataxias 2, 19. doi: 10.1186/s40673-015-0038-7

Conflict of Interest Statement: The author declares that the research was conducted in the absence of any commercial or financial relationships that could be construed as a potential conflict of interest.

Copyright (c) 2017 Glynn. This is an open-access article distributed under the terms of the Creative Commons Attribution License (CC BY). The use, distribution or reproduction in other forums is permitted, provided the original author (s) or licensor are credited and that the original publication in this journal is cited, in accordance with accepted academic practice. No use, distribution or reproduction is permitted which does not comply with these terms. 